\title{
How to shorten the pain-to-balloon time in the Croatian Primary Percutaneous Coronary Intervention Network
}

\author{
Matias Trbušić1*, \\ Zdravko Babić', \\ Diana Balenović \\ Andrea Grman-Fanfani ${ }^{3}$, \\ Ines Zadro², \\ Hrvoje Pintaric̄
}

'University Hospital Centre "Sestre milosrdnice", Zagreb, Croatia

${ }^{2}$ General Hospital "dr. Ivo Pedišić", Sisak, Croatia

${ }^{3}$ Karlovac General Hospital, Karlovac, Croatia
RECEIVED:

January 26, 2016

ACCEPTED:

February 20, 2016

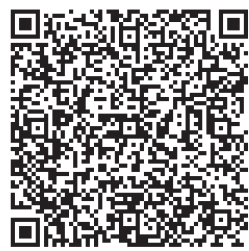

KEYWORDS: primary percutaneous coronary intervention, ST-segment elevation myocardial infarction, network, pain-to-balloon time.

CITATION: Cardiol Croat. 2016;11(3-4):109. | DOI: http://dx.doi.org/10.15836/ccar2016.109

*ADDRESS FOR CORRESPONDENCE: Matias Trbušić, Klinički bolnički centar Sestre milosrdnice, Vinogradska 29, HR-10000 Zagreb, Croatia. / Phone: +385-99-3787-064 / E-mail: matias.trbusic@gmail.com

ORCID: Matias Trbušić, http://orcid.org/0000-0001-9428-454X • Zdravko Babić, http://orcid.org/0000-0002-7060-8375 Diana Balenović, http://orcid.org/0000-0001-8182-6848 • Hrvoje Pintarić, http://orcid.org/0000-0002-7741-4194

IIIIIIIIIIIIIIIIIIIIIIIIIIIIIIIIIIIIIIIIIIIIIIIIIIIIIIIIIIIIIIIIIIIIIIIIIIIIIIIIIIIIIIIIIIIIIIIIIIIIIIIIIIIIIIII

Early performance of primary percutaneous coronary intervention (PCI) in patients with ST-segment elevation myocardial infarction is important in minimizing the ischemic insult and infarct size of the myocardium. In addition, the prevalence of slow or no-reflow phenomenon is significantly higher when the duration between chest pain onset and reperfusion (PTB; pain-to-balloon time) was more than 4 hours. Although the latest guidelines recommend less than 90 minutes of door-to-balloon (DTB) time, they strongly emphasize the importance of its shortening. But obviously, the PTB time is more influenced by pain to door (PTD) time than by DTB time. It is shown that the patients with DTB time of $<90$ minutes and PTD time of $<4$ hours had the lowest long term mortality (3.51\%). ${ }^{1}$ The results of Croatian Primary PCI Network are shown to be comparable to result of similar PCI networks of economically more developed countries. ${ }^{2,3}$

Our ongoing study is trying to find the epidemiological, social and organizational factors that are mostly influencing both PTD time and DTB time in North-West Croatia. The study is ongoing in two hospitals without PCI capability and their referral PCI capable hospital, investigating patients from rural and urban areas. The results of this study will help in identification of weak links in chain called PTB time and definition of possible targets for further improvements in Croatian PCI network.

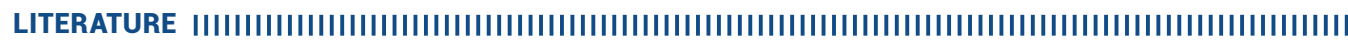

1. Hannan EL, Zhong Y, Jacobs AK, Holmes DR, Walford G, Venditti FJ, et al. Effect of onset-to-door time and door-to-balloon time on mortality in patients undergoing percutaneous coronary interventions for st-segment elevation myocardial infarction. Am J Cardiol. 2010;106(2):143-7. DOI: http://dx.doi.org/10.1016/j.amjcard.2010.02.029

2. Nikolić Heitzler V, Babic Z, Milicic D, Bergovec M, Raguz M, Mirat J, et al. Results of the Croatian Primary Percutaneous Coronary Intervention Network for patients with ST-segment elevation acute myocardial infarction. Am J Cardiol. 2010 May 1;105(9):1261-7. DOI: http://dx.doi.org/10.1016/j.amjcard.2009.12.041

3. Nikolić Heitzler VN, Babić Z, Milicić D, Starcević B, Mirat J, Strozzi M, et al. Evaluation of importance of door-to-balloon time and total ischemic time in acute myocardial infarction with ST-elevation treated with primary percutaneous coronary intervention. Acta Clin Croat. 2012:51(3):38795. PubMed: http://www.ncbi.nlm.nih.gov/pubmed/23330404 